\title{
CORRESPONDENCE
}

\section{Tumour surveillance in beige mice}

SIR, - Since beige mice have been shown to have defective natural killer (NK) cells ${ }^{1}$, several groups have reported recently in Nature on the presumed consequences - viz. poor immuno-surveillance for spontaneous tumours in mice 3,4 and men ${ }^{4}$. Padgett ${ }^{5}$ reviewing Chediak-Higashi-syndrome of man, mink and cattle noted raised incidence of lymphoma. Beige mice are the murine equivalent. The gene, $b g^{J}$, was long ago obtained from the Jackson Laboratory on its C57 BL background and in this laboratory crossed onto $\mathrm{a}\left(\mathrm{C}_{3} \mathrm{H} \times 101\right) \mathrm{F}_{1}$ background and maintained thus. Neither of these Harwell strains nor the $F_{1}$ is noted for natural lymphoma. After the reported NK defect in C57 BL bg bg, 40 Harwell beige mice were set aside for life-time study. Others had been used for determining the origin of the osteoclast from the haematopoietic stem cell6,7 during which electron microscopy studies of their bones had revealed $C$ type virus, often in substantial numbers, in young mice. Of the $\mathbf{4 0}$ mice, now aged $15-18$ months, $11(27 \%)$ have died or been killed with a variety of disseminated lymphomas. The remainder suffer from ataxia noted around the age of one year and currently under investigation. Yours faithfully,

J.F. LOUTIT K.M.S. TOWNSEND J.F. KNOWLES MRC Radiobiology Unit, Harwell, Didcot, Oxon., UK

1 Roder J. and Duwe A., Nature 278, 451-453; 1979 Talmadge J.E., Meyers K.M., Prieur D.J. and Starkey J.R. Nature 284, 622-624; 1980

Kärre K., Klein G.O., Kiessling R., Klein G. and Roder J.C. Nature 284, 624-626; 1980

Roder J., Haliotis T., Kiein M., Korec S., Jett J.R. Ortaldo S., Heberman R.B., Katz P. and Fauci A.S Nature 284, 553; 1980

Padgett G.A. Adv. vel. Sci. 12, 240-284; 1968

6 Ash P., Loutit J.F., and Townsend K.M.S. J. Path (In

press). $669-670 ; 1980$

\section{What should be called a lectin?}

SiR, - During the past decade, interest in lectins (also referred to as agglutinins, phytohemagglutinins, phytoagglutinins and protectins) has increased enormously. The term lectin has frequently been used to describe substances which differ markedly from those classically considered lectins, that is plant seed carbohydrate binding proteins. Nevertheless, the discovery of lectin-like substances in widely diverse sources (bacteria, fungi, fish sera, snails, etc) appears to warrant an expansion of the term. For the sake of clarity we would suggest the following definition of "lectin".

A lectin ${ }^{1}$ (from the Latin legere: to chose) is a sugar-binding protein or glycoprotein of non-immune origin which agglutinates cells and/or precipitates glycoconjugates.

- Lectins bear at least two sugar-binding sites, agglutinate animal and plant cells (most commonly erythrocytes, unmodified or enzyme-treated) and/or precipitate polysaccharides, glycoproteins and glycolipids.

- The specificity of a lectin is usually defined in terms of the mono-saccharide(s) or simple oligosaccharides that inhibit lectin-induced agglutination (or precipitation or aggregation) reactions.
- Although first discovered in plants, lectins also have been found in many organisms from bacteria to mammals. A lectin may be soluble in biological fluids (eg concanavalin A) or membrane-bound (eg rabbit or rat liver lectins).

- There are several other types of sugarbinding proteins including sugar specific enzymes (glycosidases, glycosyltransferases, glycosylkinases, glycosylpermeases, glycosylepimerases ...), transport proteins, hormones (thyroid-stimulating hormone, follicle-stimulating hormone, ....) and toxins (ricin, abrin, modeccin ....), etc.

Under some conditions, sugar-specific enzymes with multiple combining sites agglutinate cells (and/or precipitate glycoconjugates) and so act as a lectin.

In spite of similarities to true lectins from the same source, toxins - which bear only one sugar-binding site - should not be called lectins since they do not agglutinate cells or precipitate glycoconjugates.

Yours faithfully,

IRWIN J. GoldsteIN

University of Michigan, Ann Arbor.

Michigan, US

\section{R. COLIN Hughes}

National Institute for Medical Research, Mill Hill, London, UK

Centre de Biophysique Moleculaire,

Michel Monsigny Universitie d'Orleans, France

TOSHIAKI OSAwA

Faculty of Pharmaceutical Sciences,

University of Tokyo, Japan

Nathan SHaroN

The Weizmann Institute of Sciences,

Rehovot, Israel

1. Boyd, W.C. and Slapeigh, E., Specific precipitating activity of plant agglutinins (lectins), Science 119, 419; 1954.

\section{Thought for lowly locusts}

SIR, - We were surprised, nay disappointed by the conclusion to your article (24 April, page 659) entitled 'Pores for thought', namely "There is every reason to believe . . . and will be followed by those of channels induced by a variety of neurotransmitters'. May we remind you that Nature published a paper last year entitled 'Single glutamate activated channels on locust muscle' $(278,643 ; 1979)$. Are we to believe that glutamate is not a serious contender as a transmitter? Perhaps the lowly status of locusts precludes them from serious consideration by Acting Editors of eminent journals.

Yours faithfully,

P.N.R. USHERWOOD

UK

\section{Amanda and the scientists: a verse on syntax}

SIR, - The following verses are intended to both amuse and instruct your readers, many of whom, judged by their contributions to your pages, are guilty of faults of syntax:

"Papa," said Amanda, "I want to know what These scientists mean when they write:

"The dye was identified using a plot Of $E$ against wavelength of light.'

"Or here: 'The bacilli were easily seen When using high magnification
And judging by leucocytes found in the spleen They had caused an acute inflammation.

"And in Astronom. Rev. I read: 'Bearing in mind

The value ascribed to $\log g$

Circinus X-1 is now better defined As a neutron low-mass binary.'

"But can germs use a microscope, dyestuffs a plot?

Are bacilli with judgement endowed?

Is it logs on the mind that makes neutron stars hot?

I protest that my mind's in a cloud."

Said Papa, "Your confusion is natural enough But in time you will find it amusing

To know you can always spot scientists' stuff By this typical misuse of using.

"Misattached participles are constantly seen In scientists' journals today

For scientists rarely can say what they mean $O r$, in consequence, mean what they say.

"They treat with derision linguistic precision, Their syntactical errors are massive

And chiefly because of the quaint superstition That the Voice of true Science is passive.

"Still, think of the blessings by Science bestowed:

The quasars and antibiotics;

The strontium-90, the helical code,

Carcinogens, quarks and narcotics!"

"Oh I do!" said Amanda, "Yet since you've explained

That their writings need mental translation

To be understood, I conclude that, though trained,

Most scientists lack education."

"That remark," said Papa, "though quite frequently heard

No iota of difference will make:

They language and logic abuse undeterred With a confidence nothing can shake.

"To a study of leptons or nebulous Crabs Ne'ertheless you may one day aspire.

For a start go and visit the Veterinary labs And admire what there is to admire."

"Yes I will!" said Amanda, and seizing her coat

Ran off to that innocent band

Who were busy improving Rebecca the goat By transplanting her mammary gland.

Yours faithfully, R.F. GLASCOCK With acknowledgements to Belloc.

Reading, UK

\section{Taxi illusion - explained}

SIR, - Surely the explanation of the "taxi illusion" (24 April, page 658) is as follows:Suppose the taxi is travelling at speed $V$. The passenger, looking back through the rear windscreen sees objects along the road receding at speed $V$ relative to the taxi.

Looking forward, he sees the reflected images of those objects, apparently moving forward at speed $V$ relative to the taxi.

He sees the images against a background of real objects seen through the front windscreen moving towards the taxi at speed $V$.

The reflected images therefore appear to be passing the real objects at a speed $2 \mathrm{~V}$. Yours faithfully,

J.P. FREEMAN

8. Vicarage Close, Ravensden,

Bedford, UK 